\title{
Emotional facial expression in women recovered from anorexia nervosa
}

\author{
Helen Davies*, Ulrike Schmidt and Kate Tchanturia
}

\begin{abstract}
Background: Recent models of anorexia nervosa (AN) have emphasised the importance of social and emotional difficulties as maintenance factors of the disorder, however, empirical data are limited. The aim of this study was to examine whether altered emotional facial expression, previously observed in people currently ill with anorexia nervosa, is limited to the ill state or present in people recovered from the illness.

Methods: The sample consisted of 123 participants [49 AN, 21 recovered AN (RecAN) and 53 healthy controls (HC)]. Participants watched three films clips (amusing, neutral, sad) whilst their facial expressions were recorded and completed the positive and negative affect scale (PANAS) to record subjective experience. Facial expressions were subsequently coded for frequency of positive and negative expression and frequency of looking away.

Results: In response to the amusing clip, AN participants showed significantly less positive expression than both $\mathrm{HC}$ and RecAN groups and both AN and RecAN showed more negative expression than $\mathrm{HC}$ with no difference between groups in looking away.

In response to the sad clip there was no difference between groups in positive expression, but current AN participants showed significantly less negative expression than $\mathrm{HC}$ and looked away from the stimuli more than RecAN or HC. In terms of their subjective emotional experience, patients with current AN reported less positive emotion in response to both the amusing and the sad film clip. There was no difference between groups in subjective negative experience.

Conclusions: Alterations in facial expression are present in people currently ill with AN contributing to the social difficulties found in AN and potentially exacerbating resistance to treatment. Some alterations in facial expression are found in women with a past history of AN but not to the same extent as those shown in the currently ill group. Future studies need to use a wider range of stimuli involving different emotions to corroborate findings.
\end{abstract}

Keywords: Anorexia, Recovered, Emotion, Facial expression, Eating disorders

\section{Background}

Anorexia nervosa (AN) is a disorder with major psychological, physical and social sequelae [1] as well as high mortality [2]. However, progress in the treatment of adults with AN remains limited [3,4]. Recent maintenance models [5], supported by experimental and self-report studies [6-9], highlight significant and wide ranging impairments in the socio-emotional domain in people currently ill with AN. Such maintaining factors may contribute to the resistance to treatment. For example, there is altered emotional facial expression [8], which can impact on effective emotion regulation and social

\footnotetext{
* Correspondence: helen.davies000@gmail.com

Division of Psychological Medicine, King's College London, Institute of Psychiatry, De Crespigny Park, PO59, London SE5 8AF, UK
}

interaction [10-12]. A major problem, however, with undertaking research in patients currently ill with $\mathrm{AN}$, is the confounding effect of starvation, and thus low body mass index (BMI), on potential aetiological factors, such as altered emotional expression. For example, starvation in healthy people has been shown to be associated with various socio-emotional related changes [13].

As a first step in disentangling state and trait factors, cross sectional comparisons of ill and recovered patients can be of use. This is the strategy employed here to investigate whether altered emotional facial expression [8] is present in people with a past history of AN. Studies of facial expression in other clinical groups [schizophrenia and post traumatic stress disorder (PTSD)] of people who are in remission $[14,15]$ or who are at risk of mental illness

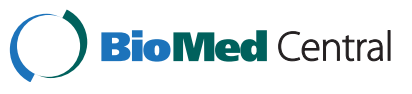


[16] provide tentative support for alterations in emotion expressivity serving as a trait vulnerability factor for these disorders.

In anorexia nervosa, there is some evidence for trait related socio-emotional difficulties from retrospective studies which have investigated premorbid temperament characteristics. Although no studies have focussed specifically on premorbid deficits in emotional facial expression, studies have reported negative emotionality and inhibition of emotion [17], impairment in interpersonal functioning [18] and shyness and limited social networks [19] in people who later developed AN. In addition, 20\% of individuals with $\mathrm{AN}$ report social anxiety before the onset of their eating disorder [20].

Studies with recovered AN individuals also highlight distinct emotional and interpersonal features such as behavioural avoidance, submissive behaviour [21,22] and difficulties recognising emotion in others [23]. However, other studies have shown that recovered AN show no differences to $\mathrm{HC}$ in emotion recognition [24]. Therefore, further studies are required to establish whether socio emotional difficulties are present in recovery or can be only observed in the ill state.

In summary, limited studies in AN show that socioemotional difficulties, which occur in the acute phase of the illness, are present premorbidly, and to some extent following recovery. Many of these studies are using self report questionnaires (e.g. [21,22]) or focus on emotion recognition (e.g.,[23]). Given the importance of emotion expression for effective communication and self regulation, the investigation of whether such behavioural attributes constitute an integral part of the patients' personality and thus contribute to the pathogenesis of $\mathrm{AN}$, is important to develop more accurate and refined illness models.

\section{Aim}

This study employs an experimental method to address whether alterations in emotional facial expression are associated with the acutely ill stage or whether these alterations are present in people recovered from AN. It was hypothesised that people recovered from AN would show some problems with emotional facial expression reflecting the possibility of trait alterations.

\section{Methods}

Ethical approval was obtained through the Oxfordshire Rec NHS ethics committee (reference 08/H0606/58) and the research is in compliance with the Helsinki Declaration.

\section{Participants}

All participants were female and eligible to take part if they were aged between 16 and 55 years old (as the ED unit where recruitment took place treats people in this age range). AN participants were recruited from the South London and Maudsley NHS Foundation Trust's (SLaM) Eating Disorders Service, through posters placed in the local community and through a circular e-mail to staff and students at King's College, London. For inclusion in this group, participants had to have a BMI $\left(\mathrm{kg} / \mathrm{m}^{2}\right)$ below 18.5 and be diagnosed by experienced clinicians as fulfilling DSM-IV (24) criteria for AN. The decision to include this weight limit is based on a recent large meta-analysis which suggests that $\mathrm{AN}$ with a more lenient weight criterion and without amenorrhoea is very similar to strict diagnostic $\mathrm{AN}$, as long as $\mathrm{BMI}<$ 18.5 is set [25].

Inclusion criteria for the healthy control group included a BMI of between 19 and 25, no personal or family history of psychiatric illness, DSM-IV Axis I disorder or a past or current eating disorder.

For the recovered AN group (RecAN), the structured clinical interview for DSM-IV disorders (SCID) [26] confirmed that participants had previously had AN. Recovery was defined as the absence of eating disorder pathology, together with a BMI of $\geq 19 \mathrm{~kg} / \mathrm{m}^{2}$ and regular, restored menstruation for at least one year prior to the assessment. Furthermore, recovered participants were required to obtain a score below the clinical cut off of 3 on the Eating Disorders Examination Questionnaire (EDE-Q) [27]. The SCID also determined that the RecAN group did not meet criteria for any current DSM-IV diagnosis.

Exclusion criteria for all groups included poor literacy as defined by the National Adult Reading Test (NART) [28], non-fluent English, a history of head injury or neurological disease.

Based on the pilot study of Davies et al. [8], the power calculation indicates that a sample size of 15 participants in each group would have $80 \%$ power to detect significant differences $(d=1.096)$ between groups with a 0.05 twotailed significance level.

\section{Measures and procedure}

All participants gave written, informed consent to take part, after receiving a full explanation of what the study entailed. Self-report questionnaires were completed prior to meeting with the researcher.

\section{Demographic and clinical information}

Participants recorded their age, medication status and ethnicity. Participants' weight and height was recorded and, in addition, duration of illness and lowest weight was obtained for the recovered and currently ill AN participants. The EDE-Q [27], and Depression, Anxiety and Stress Scale (DASS) [29], were completed by participants. 


\section{Experimental task - films task}

Film clips have previously been used by us and other groups as a means to elicit facial emotion expression e.g. $[8,30]$. Films were chosen as an ecologically valid method for eliciting emotion and do not rely on participants' ability to recall past experiences, and unlike slides or photographs, provide a more realistic context in which emotional experiences typically develop over time. Three film clips were used, a positive film clip taken from "Four Weddings and a Funeral", a negative film clip from "Shadowlands" and a neutral film clip, of simulated waves. The positive and negative film clips were selected from a total of 11 after being viewed by 20 people who met $\mathrm{HC}$ criteria. The film clips were selected based on eliciting the highest positive and negative scores on the PANAS. Each clip lasts $2 \mathrm{~min}$. Films were presented in a fixed order of positive, neutral, and negative. This is based on the premise that negative affect has a more lasting carry over effect. Participants viewed the clips on the same day and they were presented on a 15-inch computer screen.

\section{Procedure}

While viewing each film clip, participants' faces were recorded with their knowledge and agreement, using a small camera fixed onto the computer screen. Participants were instructed to "allow themselves to get into the story" as much as possible. This line of instruction was intended to allow participants to attend to the film without revealing the true nature of the study in order to reduce demand characteristics [31]. Following the positive and negative film clip, participants completed the positive and negative affect scale (PANAS) [32]. Because the neutral film clip was primarily included to minimize affect and thus reduce carry over effects between the positive and negative film clips, PANAS ratings were not obtained after the showing of this clip.

\section{Coding the facial expressions}

Recordings of participants were coded using the Facial Expression Coding System (FACES) [33]. In FACES, an expression is defined as any change in the face from a neutral display (i.e. no expression) to a non-neutral display and back to a neutral display. If the participant shifts from neutral to non-neutral but does not return to a neutral display but evidences another clear display of affective expression, this is coded as an additional expression. Each time a separate expression occurs, coders' rate whether it is a positive or negative expression (valence) and a frequency count of expression is initiated. The intensity of the expression is also assessed using a 4-point Likert scale ( $1=$ low, 4 = very high) as is duration (in seconds). In addition, the frequency of "looking away" is also counted. At the end of each clip, coders compute the following information (1) the total number (frequency) of positive expressions, their mean intensity, and mean duration; (2) the total number of negative expressions, their mean intensity, and mean duration; (3) the total number of times looking away. Two researchers rated the participants' facial expressions. Inter-rater agreement between coders was medium size $(\mathrm{k}=.63)$, which is regarded as substantial agreement [34].

\section{Analysis}

Normality of data was assessed using the KolmogorovSmirnoff test and inspection of histograms. Not all variables in the experimental data met parametric assumptions. Data which were positively skewed were log transformed. Experimental data were then analysed using a repeated measures design with planned pairwise comparisons. Where the demographic and clinical data did not meet parametric assumptions, non-parametric Kruskal-Wallis alternatives were used with Mann Whitney U tests to compare groups at the post hoc level. Cohen's $d$ effect sizes were calculated using means and standard deviations and were defined as small $(\mathrm{d} \leq 0.4)$, medium $(\mathrm{d}>0.4)$ or large $(\mathrm{d}>0.8)$. Non-parametric Spearman rank correlation coefficient investigated the relationships between task performance and demographics and clinical symptomatology. Correlations were conducted at the group level.

\section{Results}

Table 1 shows the final study sample which consisted of 123 participants (49 AN, 21 RecAN and $53 \mathrm{HC}$ ). The AN participants form an extended group who were reported in a previous study [8].

\section{Demographic and clinical outcomes}

Of the RecAN group, 57\% were recruited from King's College London and the remainder from the community. Of the AN participants, $74 \%$ were inpatients, $14 \%$ outpatients and $12 \%$ recruited from the largest UK charity for eating disorders B-eat.

As illustrated in Table 1, all three groups were comparable in age and IQ. The RecAN group were comparable in $\mathrm{BMI}$ to the $\mathrm{HC}$ group which was significantly higher than the AN participants. The AN group had a significantly longer duration of illness (10.9 years) than the RecAN (5.5 years), however, there was no significant difference in each of the groups' lowest BMI since the onset of illness. In terms of clinical variables, as expected the AN group scored significantly higher in eating pathology, depression, anxiety and obsessive compulsiveness than the $\mathrm{HC}$ and RecAN groups. The RecAN group scored significantly higher than the $\mathrm{HC}$ group on these measures, however, their scores were not in the clinical range. Concerning medication, 39\% of the AN group were taking psychotropic medication as were $19 \%$ of the RecAN group. 
Table 1 Demographic and clinical features for AN, RecAN and HC participants

\begin{tabular}{|c|c|c|c|c|c|c|c|}
\hline & AN $(n=49) M(S D)$ & $\operatorname{RecAN}(n=21) M(S D)$ & $H C(n=53) M(S D)$ & Test statistic & $p$ value & Post hoc difference & Cohen's d ES \\
\hline Age & $25.9(6.8)$ & $28.4(8.7)$ & $26.4(8.4)$ & $x^{2}=1.3$ & $n / s$ & $p>0.01$ & $\mathrm{n} / \mathrm{a}$ \\
\hline \multirow[t]{3}{*}{ NART } & 109.2(8.1) & $112.4(7.5)$ & $113.7(5.9)$ & $F=10.5$ & $n / s$ & $\mathrm{AN}=\mathrm{HC}$ & 0.91 \\
\hline & & & & & & $A N=\operatorname{Rec} A N$ & 0.66 \\
\hline & & & & & & $\mathrm{RecAN}=\mathrm{HC}$ & 0.20 \\
\hline \multirow[t]{3}{*}{ BMl } & $14.7(1.9)$ & $21.0(2.2)$ & $21.6(1.6)$ & $F=01.5$ & $<.001$ & $\mathrm{AN}<\mathrm{HC} * *$ & 3.92 \\
\hline & & & & & & AN $<$ RecAN $* *$ & 3.06 \\
\hline & & & & & & $\mathrm{RecAN}=\mathrm{HC}$ & 0.31 \\
\hline Illness length & $10.1(6.3)$ & $5.5(3.5)$ & $\mathrm{n} / \mathrm{a}$ & $U=204.5$ & $<.001$ & AN $>\operatorname{Rec} \mathrm{AN}^{* *}$ & 0.90 \\
\hline Lowest BMI & $14.4(2.8)^{b}$ & $13.6(2.1)^{c}$ & $\mathrm{n} / \mathrm{a}$ & $U=142.0$ & $n / s$ & $p>0.01$ & $\mathrm{n} / \mathrm{a}$ \\
\hline \multirow[t]{3}{*}{${ }^{\mathrm{a}} \mathrm{EDE}-\mathrm{Q}$} & $3.8(1.7)$ & $1.5(1.0)$ & $0.6(0.6)$ & $X^{2}=64.5$ & $<.001$ & $\mathrm{AN}>\mathrm{HC}^{* *}$ & 2.51 \\
\hline & & & & & & AN $>\operatorname{RecAN} * *$ & 1.64 \\
\hline & & & & & & $\operatorname{RecAN}>\mathrm{HC}^{*}$ & 1.09 \\
\hline \multirow[t]{3}{*}{ aDASS anxiety } & 21.4(10.9) & $5.7(6.5)$ & $2.2(3.2)$ & $X^{2}=66.0$ & $<.001$ & $\mathrm{AN}>\mathrm{HC}^{* *}$ & 2.39 \\
\hline & & & & & & AN $>\operatorname{Rec} \mathrm{AN}^{* *}$ & 1.74 \\
\hline & & & & & & $\operatorname{RecAN}>\mathrm{HC}^{*}$ & 0.68 \\
\hline \multirow[t]{3}{*}{ aDASS depression } & $27.2(11.3)$ & $8.4(7.7)$ & $2.4(2.6)$ & $X^{2}=72.9$ & $<.001$ & $\mathrm{AN}>\mathrm{HC}^{* *}$ & 3.02 \\
\hline & & & & & & AN $>\operatorname{Rec} A N^{* *}$ & 2.00 \\
\hline & & & & & & RecAN $>\mathrm{HC}^{*}$ & 1.04 \\
\hline
\end{tabular}

M=Means; $S D=$ standard deviation; $A N$ = anorexia nervosa; RecAN = recovered AN; HC = healthy controls; NART National Adult Reading Test; BMI Body Mass Index; EDE-Q Eating Disorders Examination; DASS Depression, Anxiety and Stress Scale - HC were excluded if scoring above 9 for depression and 7 for anxiety; $\mathrm{ES}=$ Effect Size; $\mathrm{U}=$ Mann Whitney U Test; $\mathrm{X} 2=$ Kruskal Wallis Test $\mathrm{F}=$ Analysis of Variance Test $\mathrm{a}=6 \mathrm{AN}$ missing, $3 \mathrm{HC}$ missing; $\mathrm{b}=23 \mathrm{missing}, \mathrm{c}=8$ missing; ${ }^{*}$ comparison significant at $\mathrm{p}<0.01$ level; ${ }^{* *}$ comparison significant at $\mathrm{p}<0.001$ level, $\mathrm{ns}=$ non-significant.

\section{Experimental paradigm outcomes}

There was an overall high correlation between each of the three dependent variables (frequency, intensity and duration) for positive and negative expression. Because of this, and like other studies that have used the FACES system (e.g.[31]) we used "frequency" as the prime index of emotional expressivity in order to reduce the number of highly correlated dependent variables.

\section{Frequency of emotional expressivity}

A three (AN vs RecAN vs HC) x three (amusing, sad, neutral) repeated measures ANOVA was conducted separately for frequency of positive and negative expressiveness, with group as a between subjects factor and film type as a within subjects factor. Table 2 summarises mean scores, standard deviations and effect sizes for each of the experimental variables.

\section{Positive expression}

For positive expressivity the data met parametric assumptions. There was a significant main effect for film type $\left[\mathrm{F}(2,240)=379.8, \mathrm{p}<.001\right.$, partial $\left.\varepsilon^{2} 0.8\right]$ and for group $\left[\mathrm{F}(2,120)=37.9, \mathrm{p}<.001\right.$, partial $\left.\varepsilon^{2} 0.38\right]$. The response pattern to film type differed between groups as the significant film type $\mathrm{x}$ group interaction revealed [F $(4,240)=37.0, \mathrm{p}<.001$, partial $\left.\varepsilon^{2} 0.4\right]$. Planned pairwise comparisons showed there was a significant difference in the frequency of positive expression in response to the amusing film between $\mathrm{AN}$ and $\mathrm{HC}$ groups (mean difference $7.0,95 \%$ confidence interval [CI] 5.3 to 8.6 , $\mathrm{p}<.001, \mathrm{~d}=1.72$ ) with $\mathrm{HC}$ showing higher frequency of positive expressions. Also between the AN and RecAN groups (mean difference 4.6, 95\% CI 2.5 to 6.7, $\mathrm{p}<.001$, $\mathrm{d}=1.10$ ) with RecAN showing more positive expressions. There was no significant difference between the RecAN and $\mathrm{HC}$ groups $(\mathrm{p}=.12)$.

In response to the sad and neutral film clips there was no significant difference in positive expression between the groups as $\mathrm{p}>0.01$.

\section{Negative expression}

Data were log transformed due to non normal distribution and unequal variances. There were significant main effects for film type $\left[\mathrm{F}(2,240)=68.8, \mathrm{p}<.001\right.$, partial $\left.\varepsilon^{2} 0.4\right]$ and for group $\left[\mathrm{F}(2,120)=158.7, \mathrm{p}<.05\right.$, partial $\left.\varepsilon^{2} .05\right]$. The response pattern to film type between groups differed as the significant film type $\mathrm{x}$ group interaction showed $\left[\mathrm{F}(4,240)=15.4, \mathrm{p}<.001\right.$, partial $\left.\varepsilon^{2} 0.2\right]$. A planned pairwise comparison showed there was a significant difference in frequency of negative expression in response to the sad film clip between the AN and HC groups (mean difference $0.27,95 \% \mathrm{CI} 0.2$ to $0.4, \mathrm{p}<.001, \mathrm{~d}=1.1$ ) with the $\mathrm{AN}$ group showing less negative expression to the sad film clip 
Table 2 Facial expression and PANAS response to film clips for AN, RecAN and HC participants

\begin{tabular}{|c|c|c|c|c|c|c|c|c|c|c|c|c|c|c|}
\hline & \multicolumn{5}{|c|}{ Amusing film clip } & \multicolumn{5}{|c|}{ Sad film clip } & \multicolumn{4}{|c|}{ Neutral film clip } \\
\hline & $\begin{array}{l}\text { AN }(n=49) \\
\text { M (SD) }\end{array}$ & $\begin{array}{l}\text { RecAN (n=21) } \\
M(S D)\end{array}$ & $\begin{array}{l}H C(n=53) \\
M(S D)\end{array}$ & $\begin{array}{l}\text { post hoc } \\
\text { differences }\end{array}$ & $\begin{array}{l}\text { Cohen's } \\
d \text { ES }\end{array}$ & $\begin{array}{l}\text { AN }(n=49) \\
M(S D)\end{array}$ & $\begin{array}{l}\text { RecAN (n=21) } \\
M(S D)\end{array}$ & $\begin{array}{l}H C(n=53) \\
M(S D)\end{array}$ & $\begin{array}{l}\text { post hoc } \\
\text { differences }\end{array}$ & $\begin{array}{l}\text { Cohen's } \\
d \text { ES }\end{array}$ & $\begin{array}{l}\text { AN (n=49) } \\
M(S D)\end{array}$ & $\begin{array}{l}\text { RecAN (n=21) } \\
M(S D)\end{array}$ & $\begin{array}{l}H C(n=53) \\
M(S D)\end{array}$ & $\begin{array}{l}\text { post } \\
\text { hoc }\end{array}$ \\
\hline \multirow{3}{*}{$\begin{array}{l}\text { Positive } \\
\text { expression }{ }^{1}\end{array}$} & 4.0 & 8.6 & 11.0 & $\mathrm{AN}<\mathrm{HC} * *$ & 1.72 & 0.1 & 0.2 & 0.3 & $p>0.01$ & & 0 & 0 & 0 & $p>0.01$ \\
\hline & $(4.1)$ & $(4.2)$ & $(4.0)$ & AN $<$ RecAN** & 1.10 & $(0.3)$ & $(0.5)$ & $(0.8)$ & & & (0) & (0) & $(0.2)$ & \\
\hline & & & & $\mathrm{RecAN}=\mathrm{HC}$ & 0.50 & & & & & & & & & \\
\hline \multirow{3}{*}{$\begin{array}{l}\text { Negative } \\
\text { expression' }\end{array}$} & 0.8 & 1.0 & 0.2 & $\mathrm{AN}>\mathrm{HC}^{*}$ & 0.59 & 0.8 & 1.6 & 2.9 & $\mathrm{AN}<\mathrm{HC}^{* *}$ & 1.13 & 0 & 0 & 0 & $p>0.01$ \\
\hline & (1.3) & (1.3) & $(0.7)$ & $A N=\operatorname{Rec} A N$ & 0.15 & (1.4) & (2.0) & (2.2) & $A N=\operatorname{Rec} A N$ & 0.46 & $(0.2)$ & $(0.2)$ & $(0.2)$ & \\
\hline & & & & RecAN $>\mathrm{HC}^{*}$ & 0.74 & & & & $\mathrm{RecAN}=\mathrm{HC}$ & 0.61 & & & & \\
\hline \multirow{3}{*}{$\begin{array}{l}\text { Looking } \\
\text { away }^{1}\end{array}$} & 0.9 & 0.2 & 0.5 & $p>0.01$ & & 4.6 & 1.6 & 0.6 & $\mathrm{AN}>\mathrm{HC}^{* *}$ & 1.11 & 2.6 & 1.7 & 3.2 & $p>0.01$ \\
\hline & $(2.0)$ & $(0.5)$ & (1.9) & & & $(5.0)$ & $(2.5)$ & (1.0) & AN $>$ RecAN** & 0.75 & $(4.6)$ & $(2.1)$ & (6.5) & \\
\hline & & & & & & & & & $\mathrm{RecAN}=\mathrm{HC}$ & 0.52 & & & & \\
\hline \multirow{3}{*}{$\begin{array}{l}\text { PANAS } \\
\text { positive }^{2}\end{array}$} & 11.2 & 13.8 & 16.9 & $\mathrm{AN}<\mathrm{HC}^{* *}$ & 0.86 & 4.6 & 7.0 & 7.1 & $\mathrm{AN}<\mathrm{HC}^{*}$ & 0.52 & - & - & - & \\
\hline & $(6.7)$ & $(6.0)$ & $(6.5)$ & $\mathrm{AN}=\mathrm{Rec} A \mathrm{~N}$ & 0.40 & (4.4) & (6.6) & $(4.6)$ & $A N=\operatorname{Rec} A N$ & 0.42 & & & & \\
\hline & & & & $\mathrm{Rec} A \mathrm{~N}=\mathrm{HC}$ & 0.50 & & & & $\mathrm{RecAN}=\mathrm{HC}$ & 0.01 & & & & \\
\hline \multirow{2}{*}{$\begin{array}{l}\text { PANAS } \\
\text { negative }^{2}\end{array}$} & 3.0 & 1.1 & 1.0 & $p>0.01$ & & 7.6 & 7.1 & 6.5 & $P>0.01$ & & - & - & - & \\
\hline & $(4.0)$ & (2.0) & (2.3) & & & $(7.3)$ & (5.1) & $(4.8)$ & & & & & & \\
\hline
\end{tabular}

$\mathrm{M}=$ Means; $\mathrm{SD}=$ standard deviations presented in brackets; $\mathrm{AN}=$ anorexia nervosa; RecAN=recovered anorexia nervosa; $\mathrm{HC}=$ healthy controls; PANAS = positive and negative affect scale; $\mathrm{ES}=$ effect size; ${ }^{1}$ frequency count; ${ }^{2}$ PANAS not recorded subsequent to neutral film clip; ${ }^{*}=p<.01,{ }^{* *}=p<.001$. 
than the $\mathrm{HC}$ group. There was no significant difference between RecAN and HC ( $\mathrm{p}=0.7)$.

In response to the positive film clip, negative expression significantly differed between the AN and $\mathrm{HC}$ groups (mean difference $0.12,95 \%$ CI 0.4 to $2.0, \mathrm{p}<.004, \mathrm{~d}=0.5$ ) and between the RecAN and $\mathrm{HC}$ groups (mean difference $0.12,95 \%$ CI 0.07 to $0.3, \mathrm{p}<.001, \mathrm{~d}=0.7$ ) with the AN participants and RecAN group showing higher frequency of negative expression towards the amusing film clip than the $\mathrm{HC}$ group.

There was no difference in negative expression in response to the neutral film clip between groups.

\section{Looking away}

A significant main effect was found for film type $\left[\mathrm{F}(2,240)=8.7, \mathrm{p}<.001\right.$, partial $\left.\varepsilon^{2} .07\right]$ and for group $\left[\mathrm{F}(2,120)=4.2, \mathrm{p}=.02\right.$, partial $\left.\varepsilon^{2} .07\right]$ and a significant interaction between filmtype $x$ group $[F(4,240)=74.9$, $\mathrm{p}<.001$, partial $\left.\varepsilon^{2} .10\right]$. Planned pairwise comparisons showed no significant difference between groups in looking away from the amusing film clip but there were in response to the sad film clip between the AN and RecAN groups (mean difference 3.0, 95\% CI 1.3 to $4.8, \mathrm{p}<.001, \mathrm{~d}=0.7$ ) and between the AN and $\mathrm{HC}$ groups (mean difference 4.0, 95\% CI 2.6 to $5.3, \mathrm{p}<.001, \mathrm{~d}=1.1$ ) with the AN group looking away more from the sad film clip than the RecAN and HC groups. There was no significant difference between the RecAN and $\mathrm{HC}$ in looking away from the sad film clip $(\mathrm{p}=.12)$.

There were no significant differences in frequency of looking away from the neutral film clip as $\mathrm{p}>0.01$.

\section{Emotional experience \\ Positive affect (PANAS)}

There were significant main effects for filmtype $[\mathrm{F}(1,119)=$ 188.7, $\mathrm{p}<.001$, partial $\left.\varepsilon^{2} 0.6\right]$ and for group $[\mathrm{F}(2,119)=8.7$, $\left.\mathrm{p}<.001, \varepsilon^{2} 0.1\right]$ and a significant interaction between filmtype and group $\left[\mathrm{F}(2,119)=4.6, \mathrm{p}<.01\right.$, partial $\left.\varepsilon^{2} .10\right]$. Planned pairwise comparisons showed there was a significant difference in subjective positive response to the amusing film clip between the $\mathrm{AN}$ and $\mathrm{HC}$ groups (mean difference 5.6, 95\% CI 3.1 to $8.2, \mathrm{p}<.001, \mathrm{~d}=0.8$ ) with the $\mathrm{HC}$ reporting higher positive affect. There was no significant difference between the RecAN and AN groups ( $\mathrm{p}=.14, \mathrm{~d}=0.3$ ) or RecAN and $\mathrm{HC}$ group $(\mathrm{p}=0.6$, $\mathrm{d}=0.5$ ). Regarding positive subjective response towards the sad film clip there was a significant difference between the $\mathrm{HC}$ and $\mathrm{AN}$ participants (mean difference 2.5, 95\% CI 0.6 to $4.3, \mathrm{p}<.01, \mathrm{~d}=0.5$ ) with the $\mathrm{HC}$ group reporting a higher level of positive affect towards the sad film clip. There was no significant difference between the RecAN and $\mathrm{HC}$ groups.

\section{Negative affect (PANAS)}

There was a significant main effect for filmtype $[\mathrm{F}(1,119)=$ 198.2, $\mathrm{p}<.001]$ but not for group $[\mathrm{F}(2,119)=2.0, \mathrm{p}=.14]$. Therefore, no further planned pairwise comparisons were conducted.

\section{Assessing age as a confound}

Although there was not a significant difference in age between groups, mean age was higher in the RecAN group. Expressivity has been shown to decrease with age, therefore, it was deemed appropriate to run the repeated measures analysis including age as a covariate. Age did not significantly contribute to the significant main effect for group for positive expression $[F(1,119)=0.0, p=.99]$ or for negative expression $(F(1,119)=0.28 \mathrm{p}=.60)$ and the main effect between groups remained significant.

\section{Medication}

The analyses for the experimental outcomes were run comparing medicated to un-medicated participants. Nineteen people in the AN group were taking antidepressants. There were no significant differences between medicated and un-medicated people in frequency of positive expression $(\mathrm{p}=.46)$, negative expression $(\mathrm{p}=.44)$, looking away $(\mathrm{p}=.38)$, subjective positive affect $(\mathrm{p}=.53)$ or negative subjective affect $(\mathrm{p}=.92)$. Four people in the RecAN group were taking antidepressants. There were no significant differences between medicated and un-medicated people in frequency of positive expression $(\mathrm{p}=.32)$, negative expression $(\mathrm{p}=.22)$, looking away $(.89)$, positive affect $(.08)$ or negative affect (.54). Therefore, expressive alteration does not appear to be a function of medication status.

\section{Correlational analysis}

Relationships between facial expression and clinical variables Correlations were run within each group and the only significant relationships were found within the AN group. Positive facial expression was negatively related to depression $\left(\mathrm{r}_{\mathrm{s}}=-.30, \mathrm{p}<.001\right)$ and anxiety and depression were negatively related to positive expression to the sad film $\left(\mathrm{r}_{\mathrm{s}}=-.40, \mathrm{p}<.001\right),\left(\mathrm{r}_{\mathrm{s}}=-.47, \mathrm{p}<.001\right)$, respectively. This suggests that the higher the depression the lower the display of positive facial expression to both the amusing and sad film clip. No relationships were found in the RecAN group between clinical variables and facial expression.

Relationships between subjective emotion and clinical variables In the $A N$ group there were positive moderate size correlations between negative subjective affect to the amusing film clip and anxiety $\left(\mathrm{r}_{\mathrm{s}}=.45\right)$ and depression $\left(\mathrm{r}_{\mathrm{s}}=.54\right)$. This is interpreted as the more clinically symptomatic the less positive emotion is felt in response 
to the amusing film clip. All correlations are significant at the $\mathrm{p}<.001$ level.

\section{Discussion}

We have previously shown altered emotional facial expression in people currently ill with AN [8]. The present study aimed to examine whether these alterations exist in individuals recovered from the illness. The key finding was that in response to the amusing film clip RecAN participants showed as much positive, but a higher frequency of negative expression (i.e. similar to the currently ill group) compared to the $\mathrm{HC}_{\text {group }}{ }^{\mathrm{a}}$.

There was no difference in response to the sad film clip between the RecAN and $\mathrm{HC}$, whereas the currently ill group showed less facial expression and looked away more from the sad film clip. It could be hypothesised, however, that the group showed less negative facial expression because they looked away more from the film clip.

Alterations shown in the AN group in response to the sad film clip, such as looking away, could be construed as an attempt to avoid any negative feelings the stimulus was evoking (see Davies et al., 2011 for further discussion on this). This is supported by previous studies, which suggest that avoidance in AN is used as a means of reducing affective states [35]. It could be speculated that avoidance of negative emotion could be a relevant factor as regards treatment resistance.

The RecAN responses to the amusing film clip are interesting, and could be interpreted in a number of ways. First, the theme of the amusing film clip, a wedding, may just be more aversive for the AN and RecAN groups. Due to longevity of illness and missed opportunities in relationships, the clip may elicit more negative feelings and behaviours. Future studies would need to use different film clips involving a range of emotions to ascertain whether negative expressions pertain to other positive stimuli. Nonetheless, it should be noted that other studies with currently ill AN groups have shown negative facial activity to appetitive stimuli, measured using electromyography and startle response [36,37].

Another potential explanation for an increase in negative facial expression to the amusing stimuli, is related to problems with facial mimicry. There is tentative evidence for emotion recognition difficulties in currently ill and RecAN individuals, with both groups showing a significantly higher social and angry-threat attentional bias [7]. Facial mimicry of emotion is the visible or non-visible use of facial musculature by an observer to match the facial gestures in another person's expression [38], this often occurs at an automatic and unconscious level and helps to synchronise emotion and thus empathy between people [39]. It could be that due to a misinterpretation and bias towards negative facial displays, facial responding is in turn inaccurate borne out in increased negative expression.

Finally, it is possible that 'scarring' effects are present in people who are recovered from AN [40] and contribute to the alterations highlighted. As the RecAN group showed a mean illness duration time of five years, scarring could be apparent with incomplete recovery of emotion expression. Longitudinal studies which assess at risk cohorts premorbidly and compare those who do or do not develop the disorder would be a more accurate way to examine these alterations and address the state/trait nature of facial expressivity to emotional stimulus.

Interestingly, the RecAN did show a similar frequency of positive expression to the amusing film as the $\mathrm{HC}$ (whereas the currently ill group showed less). It may be possible, however, that these expressions were not 'authentic'. In the facial expression literature there is a distinction between involuntary 'authentic' expressions and voluntary 'inauthentic' expressions [41], with studies showing that 'authentic' expressions lead to better social interaction [12]. The RecAN subjective reports of positive affect (measured by the PANAS) showed an intermediate profile between currently ill and $\mathrm{HC}$ groups (medium effect size) and could suggest 'strategic' as opposed to hedonic behavioural responses to amusing stimuli. It would be beneficial to understand if recovered individuals use more cognitive 'strategic' voluntary displays of positive expression, especially as social maladjustment has been suggested to still be present after recovery e.g. social anhedonia [42,43] and with impairment in interpersonal functioning in people who later developed AN [18]. Coding systems such as the Emotion Facial Action Coding System (EMFACS) [44] which make the distinction between authentic and non authentic positive expressions (based on muscle movement) should be employed in future studies.

\section{Limitations}

One of the problems with a cross sectional design is the comparability of groups. For example, the RecAN group may not originally have been as ill as the currently ill group. Although reported lowest weights for RecAN were as low as the AN group (albeit approximately half of this data was missing), illness length for RecAN was shorter and it is not known if their clinical symptomatology was as severe. Also, by the sheer fact of having recovered, these individuals may be a good prognostic group, with lower levels of risk or maintaining factors for $\mathrm{AN}$. In contrast, $74 \%$ of the AN group were recruited from an inpatient unit and thus were people at the severe and enduring end of the clinical spectrum, i.e. may be a poor prognostic group. Therefore, the RecAN group premorbidly may have shown less alteration in facial expression and be a positive factor in terms of resistance 
to treatments i.e. they show less resistance to treatment as they have better social interaction and emotion regulation skills.

Another limitation is that $19 \%$ of the recovered group were taking antidepressant medication, raising the question of how well recovered they were in terms of affective symptoms.

Finally, the sample size for the recovered group was small which may have biased findings and limits our statistical power and conclusions.

\section{Conclusion}

This study shows that alterations in emotional facial expression observed in people currently ill with AN are not as far reaching in a recovered group, however, minor alterations are present. This is in keeping with observations of personality changes and diminished desire for social interaction and positive reciprocity in the starved state and at low weight as well as a general resolution following resumption of normal eating and weight gain [13]. Alterations in facial expression in people currently ill with $\mathrm{AN}$, compared to $\mathrm{HC}$, contribute to the social and emotional difficulties shown in the illness and potentially play a role in resistance to treatment.

The negative expression to amusing stimuli observed in the RecAN group needs to be scrutinised further to see whether it is a behaviour which manifests in response to different positive stimuli. Different emotion film clips could be used for this along with a coding system such as EMFACs [44] which codes for discrete emotions and detects differences between voluntary and non voluntary facial expressions which would be helpful in answering questions about strategic versus genuine positive responses. Finally, a longitudinal study assessing facial emotion expression in patients when they are ill and when they are recovered would be a reasonable next step.

\section{Endnotes}

${ }^{a}$ N.B. In the previous study (Davies et al., 2011) the currently ill AN patients did not show significantly more negative emotional expression during the positive film clips compared to HC. This discrepancy may be explained by the larger sample size in the current study (even more so as there is a trend towards a significant difference between $\mathrm{AN}$ and $\mathrm{HC}$ in the previous study ( $\mathrm{p}$ value $=.06$ ).

\section{Abbreviations}

AN: Anorexia nervosa; RecAN: Recovered anorexia nervosa; HC: Healthy control; BMI: Body mass index; PANAS: Positive and negative affect scale; PTSD: Post traumatic stress disorder; FACES: Facial expression coding system; EMFACS: Emotional facial action coding system; ANOVA: Analysis of variance.

\section{Competing interests}

The authors declare that they have no competing interests.

\section{Authors' contributions}

$\mathrm{HD}$ contributed to the conception and design, acquisition, analysis and interpretation of data and drafting manuscript; US and KT contributed in the conception and design of the study, interpretation of the results, drafting and editing the manuscript. All authors read and approved the final manuscript.

\section{Acknowledgement}

This article presents independent research commissioned by the NIHR Biomedical Research Centre for Mental Health, South London and Maudsley NHS Foundation Trust and Institute of Psychiatry, King's College London and the National Institute for Health Research (NIHR) under its Programme Grants scheme (RP-PG-0606-1043). The views expressed in this publication are those of the authors and not necessarily those of the NHS, the NIHR or the Department of Health. HD and KT would also like to thank the BRC and Swiss Anorexia Foundation.

Received: 12 December 2012 Accepted: 12 September 2013 Published: 7 November 2013

\section{References}

1. Hjern A, Lindberg L, Lindblad F: Outcome and prognostic factors for adolescent female in-patients with anorexia nervosa: 9- to 14-year follow-up. Brit J Psychiat 2006, 189:428-32

2. Smink FR, van Hoeken D, Hoek HW: Epidemiology of Eating Disorders: Incidence, Prevalence and Mortality Rates. Curr Psychiatry Rep 2012. 10.1007/s11920-012-0282

3. Treasure J, Claudino AM, Zucker N: Eating disorders. Lancet 2010, 375:583-593.

4. Schmidt U, Oldershaw A, Jichi F, Sternheim L, Startup H, Mclntosh V, Jordan J, Tchanturia K, Wolff G, Rooney M, Landau L, Treasure J: A Randomised controlled trial of two out-patient psychological therapies for adults with anorexia nervosa. Brit J Psychiat 2012, 201:392-399.

5. Schmidt U, Treasure J: Anorexia nervosa: Valued and visible. A cognitiveinterpersonal maintenance model and its implications for research and practice. Brit J Clin Psychol 2006, 45:343-366

6. Oldershaw A, Hambrook D, Stahl D, Tchanturia K, Treasure J, Schmidt U: The socio-emotional processing stream in anorexia nervosa. Neurosci Biobehav Rev 2011, 35:970.

7. Harrison A, Sullivan S, Tchanturia K, Treasure: Emotional functioning in eating disorders: attentional bias, emotion recognition and emotion regulation. Psychol Med 2010, 40:1887-1897.

8. Davies H, Schmidt U, Stahl D, Tchanturia K: Evoked emotional expression and experience in anorexia nervosa. Int J Eat Disorder 2011, 44:531-539.

9. Hambrook D, Brown G, Tchanturia K: Emotional intelligence in anorexia nervosa. Psychiatry Res 2012. 200:12-9, http://dx.org/10.1016/j. psychres.2012. 05.017.

10. Davis J, Senghas A, Fredric B, Ochsner K: The effects of BOTOX injections on emotional experience. Emotion 2010, 10:433-440.

11. Gross JJ, Levenson RW: Hiding feelings: The acute effects of inhibiting negative and positive emotion. J Abnormal Psychology 1997, 106:95-103.

12. Schmidt KL, Cohn JF: Human facial expressions as adaptations: evolutionary questions in facial expression research. Yearb Phys Anthropol 2001, 44:3-24

13. Keys A, Brozek J, Henschel A, Mickelson O, Taylor H: The Biology of Human Starvation. Minneapolis, MN: University of Minnesota Press; 1950

14. Mattes RM, Schneider F, Heimann H, Birbaumer N: Reduced emotional response of schizophrenic patients in remission during social interaction. Schizophr Res 1995, 17:249-255.

15. Orr SP, Lasko NB, Metzger $\amalg$, Berry NJ, Ahern CE, Pitman RK: Psychophysiologic assessment of women with posttraumatic stress disorder resulting from childhood sexual abuse. J Consult Clin Psych 1998, 66:906-913.

16. Walker EF, Grimes KE, Davis DM, Smith AJ: Childhood precursors of schizophrenia: facial expressions of emotion. Am J Psychiat 1993, 150:1654-1660.

17. Lilenfeld LRR, Wonderlich S, Riso LP, Crosby R, Mitchell J: Eating disorders and personality: A methodological and empirical review. Clin Psychol Rev 2006, 26:299-320

18. Gillberg C, Rastam M: Anorexia nervosa outcome: Six-year controlled longitudinal study of 51 cases including a population cohort. Child Adol Psychiat 1992, 33:729-739. 
19. Fairburn CG, Cooper Z, Doll HA, Welch SL: Risk factors for anorexia nervosa: Three integrated case-control comparisons. Arch Gen Psychiat 1999, 56:468-476.

20. Kaye WH, Bulik CM, Thornton L, Barbarich N, Masters K: Comorbidity of anxiety disorders with anorexia and bulimia nervosa. Am J Psychiat 2004, 161:2215-2121.

21. Casper R: Personality features of women with good outcome from restricting anorexia nervosa. Psychosom Med 1990, 52:156-170.

22. Connan F, Troop N, Landau S, Campbell I, Treasure J: Poor social comparison and the tendency to submissive behaviour in anorexia nervosa. Int J Eat Disorder 2007, 40:733-739.

23. Oldershaw A, Dejong H, Hambrook D, Broadbent $H$, Tchanturia K, Treasure J, Schmidt U: Emotional processing following recovery from anorexia nervosa. Eur Eat Disord Rev 2012, 20:502-509. 10.1002/erv.2153. [Epub ahead of print] PMID: 22241653.

24. American Psychiatric Association: Diagnostic and Statistical Manual of Mental Disorders. 4th edition. Washington, DC: American Psychiatric Association; 1994.

25. Thomas JJ, Vartanian LR, Brownell KD: The relationship between eating disorder not otherwise specified (EDNOS) and officially recognized eating disorders: Meta-analysis and implications for DSM. Psychological Bull 2009, 135:407-433.

26. First M, Spitzer R, Gibbon M, Williams J: Structured Clinical Interview for DSM-IV Axis I Disorders (SCID) Research Version. New York: Biometrics Research, New York State Psychiatric Institute; 2002.

27. Fairburn CG, Beglin SJ: Assessment of eating disorders: Interview or self-report questionnaire? Int J Eat Disorder 1994, 16:363-370.

28. Nelson HE, Willison JR: The Revised National Adult Reading Test - Test manual. Windsor, UK: NFER-Nelson; 1991.

29. Lovibond SH, Lovibond PF: Manual for the Depression Anxiety Stress Scales. 2nd edition. Sydney: Psychology Foundation; 1995.

30. Orsillo S, Batten SV, Plumb JC, Luterek JA, Roessner BM: An experimental study of emotional responding in women with posttraumatic stress disorder related to interpersonal violence. J Trauma Stress 2004, 17:241-248.

31. Kring AM, Neale JM: Do schizophrenic patients show a disjunctive relationship among expressive, experiential and psychophysiological components of emotion? J Abnorm Psychol 1996, 105:249-257.

32. Watson D, Clark LA, Tellegen A: Development and validation of brief measures of positive and negative affect: The PANAS scales. J Pers Soc Psychol 1988, 54:1063-1070.

33. Kring A, Sloan D: The Facial Expression Coding System (FACES): development, validation, and utility. Psychol Assess 2007, 19:210-224.

34. Landis JR, Koch GG: The measurement of observer agreement for categorical data. Biometrics 1977, 33:159-174.

35. Wildes J, Ringham R, Marcus M: Emotion avoidance in patients with anorexia nervosa: Initial test of a functional model. Int J Eat Disord 2010, 43:398-404.

36. Friederich H, Kumari V, Uher R, Riga M, Schmidt U, Campbell I, Herzog W, Treasure J: Differential motivational responses to food and pleasurable cues in anorexia and bulimia nervosa: a startle reflex paradigm. Psychol Med 2006, 36:1327-1335.

37. Soussignan R, Jiang T, Rigaud D, Royet FP, Schaal B: Subliminal fear priming potentiates negative facial reactions to food pictures in women with anorexia nervosa. Psychol Med 2010, 40:503-514.

38. Hess U, Bourgeois P: You smile - I smile: emotion expression in social interaction. Biol Psychol 2010, 84:514-520.

39. Nummenmaa L, Glerean E, Viinikainen M, Jaaskelainen $P$, Hari R, Sams M Emotions promote social interaction by synchronizing brain activityacross individuals. PNAS 2012. 10.1073/pnas.1206095/-/ DCSupplemental.

40. Uher R, Brammer MJ, Murphy T, Campbell IC, Ng WW, Williams SCR, Treasure J: Recovery and chronicity in anorexia nervosa: brain activity associated with differential outcomes. Biological Psychiat 2003, 54:934-942.

41. Ekman $\mathrm{P}$, Oster $\mathrm{H}$ : Facial expression of emotion: Review of the literature, 1970-1983. In Nonverbal Behaviour and Communication. Edited by Siegman AW, Feldstein S. Hillsdale, NJ: Lawrence Erlbaum Associates; 1983.

42. Tchanturia K, Davies H, Harrison A, Fox J, Treasure J, Schmidt U: Altered social hedonic processing in eating disorders. Int J Eat Disorder 2012 45, 8:962-969. 10.1002/eat.22032.
43. Tchanturia K, Hambrook D, Curtis H, Jones T, Lounes N, Fenn K, Keys A, Stivenson L, Davies H: Work and social adjustment in patients with anorexia nervosa. Compr Psychiat 2012. org/10.1016/j.comppsych. .2012.03.014.

44. Ekman P, Friesen WV: Facial action coding system: a technique for the measurement of facial movement. Pao Alto, CA: Consulting Psychologists Press; 1978.

doi:10.1186/1471-244X-13-291

Cite this article as: Davies et al:: Emotional facial expression in women recovered from anorexia nervosa. BMC Psychiatry 2013 13:291.

\section{Submit your next manuscript to BioMed Central and take full advantage of:}

- Convenient online submission

- Thorough peer review

- No space constraints or color figure charges

- Immediate publication on acceptance

- Inclusion in PubMed, CAS, Scopus and Google Scholar

- Research which is freely available for redistribution

Submit your manuscript at www.biomedcentral.com/submit
C) BioMed Central 